\title{
Spontaneous Rupture of the Right Gastroepiploic Artery Immediately after Gastroscopy
}

\author{
Do Young Jung ${ }^{1}$, Hye-kyung Jung ${ }^{1}$, Yun Mi Ko ${ }^{1}$, Ayoung Lee ${ }^{1}$, Ji Taek Hong ${ }^{1}$, Chang Mo Moon' ${ }^{1}$ Seong Eun Kim', Chung Hyun Tae', \\ Ki Nam Shim', Sung Ae Jung', Ran Kim², Sun Young Choi ${ }^{2}$ \\ Department of Internal Medicine, College of Medicine, Ewha Womans University ${ }^{1}$, Department of Radiology and Medical Research Institute, \\ School of Medicine, Ewha Womans University ${ }^{2}$, Seoul, Korea
}

\begin{abstract}
Idiopathic spontaneous intraperitoneal hemorrhage is both rare and potentially fatal. The incidence of gastroepiploic artery rupture, especially a non-aneurysmal rupture, is extremely low. We report the case of an elderly woman who was mistakenly diagnosed with procedure-related bleeding after gastroscopy. A $0.3 \mathrm{~cm}$ polyp was identified and removed during the procedure. The patient later developed shock due to which gastroscopy was repeated; however, no unusual findings were observed. Therefore, abdominopelvic computerized tomography was performed and gastroepiploic artery rupture was detected. Transcatheter arterial embolization was immediately performed without laparotomy, without any complications. The bleeding was controlled, and the patient was discharged after embolization. It is important to acknowledge the possibility of spontaneous rupture of the visceral arteries in elderly individuals with hypertension or atherosclerosis, especially in the event of sudden abdominal pain or shock immediately after an endoscopic procedure. This is the first case report of idiopathic spontaneous rupture of the right gastroepiploic artery successfully managed by transcatheter arterial embolization in South Korea. (Korean J Helicobacter Up Gastrointest Res 2021;21:235-238)
\end{abstract}

Key Words: Gastroepiploic artery; Gastroscopy; Rupture; Spontaneous

\section{INTRODUCTION}

Idiopathic spontaneous intraperitoneal hemorrhage (ISH) is a rare and potentially fatal condition that can develop without trauma or any underlying diseases in elderly people. Gastroepiploic artery rupture is rare, and non-aneurysmal rupture is even rarer. Herein, we report the case of an elderly woman presenting with shock due to hemoperitoneum after a diagnostic gastroscopy, which was ultimately diagnosed as ISIH.

\section{CASE REPORT}

An 83-year-old woman with complaints of dull epigastric pain for several days underwent a gastroscopy. During the endoscopy, a $0.3 \mathrm{~cm}$ gastric polyp was observed at the lesser curvature of the midbody of the stomach. The polyp was removed using biopsy forceps,

Received: June 2, 2021 Revised: July 1, 2021 Accepted: July 3, 2021

Corresponding author: Do Young Jung

Department of Internal Medicine, College of Medicine, Ewha Womans University, 25 Magokdong-ro 2-gil, Gangseo-gu, Seoul 07804, Korea

Tel: +82-2-2650-5205, Fax: +82-2-2650-5880, E-mail: xfactorda@naver.com after which no significant bleeding was observed (Fig. 1).

She had a history of hyperlipidemia, hypertension, and a sliding hiatal hernia. She had chest pain and was diagnosed with unstable angina after coronary angiography 2 months before the gastroscopy. She underwent percutaneous coronary intervention at the proximal-middle left anterior descending coronary artery due to $90 \%$ luminal narrowing and received aspirin and clopidogrel for 2 months. Two hours after gastroscopy procedure, she presented with acute abdominal pain and dizziness due to which she was transferred
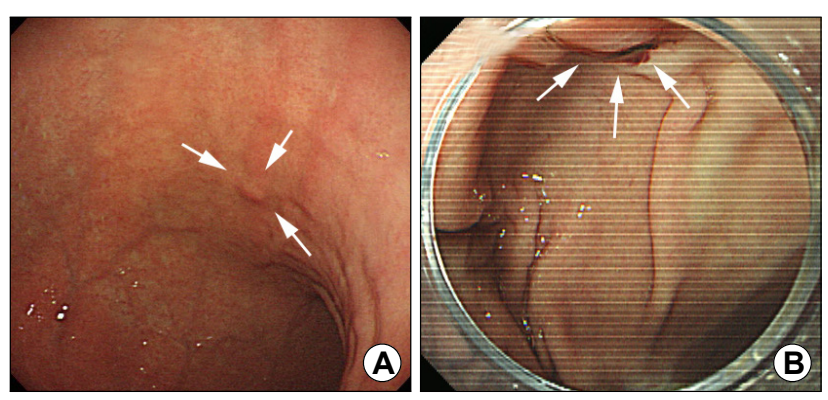

Fig. 1. Gastroscopy. (A) Arrows showing a $0.3 \mathrm{~cm}$ polyp at the lesser curvature of the mid-body is observed on initial endoscopy and removed by biopsy. (B) Arrows showing no active bleeding is observed at the previous biopsy site on the emergency endoscopy performed after the occurrence of shock.

Copyright $\odot 2021$ Korean College of Helicobacter and Upper Gastrointestinal Research

(a) The Korean Journal of Helicobacter and Upper Gastrointestinal Research is an Open-Access Journal. All articles are distributed under the terms of the Creative Commons Attribution Non-Commercial License (http:// creativecommons.org/licenses/by-nc/4.0) which permits unrestricted non-commercial use, distribution, and reproduction in any medium, provided the original work is properly cited. 


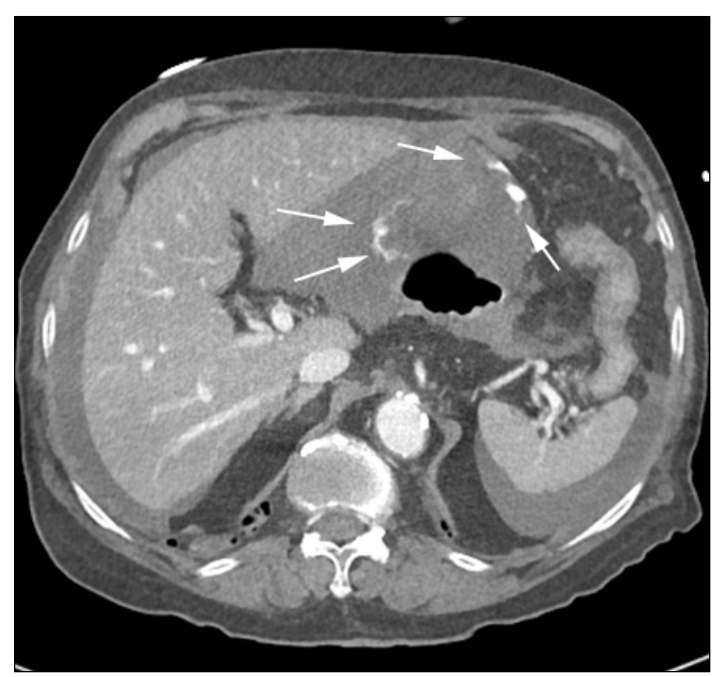

Fig. 2. Abdominal CT (axial view), arrows showing extraluminal active bleeding with hematoma around the gastric antrum without free air.

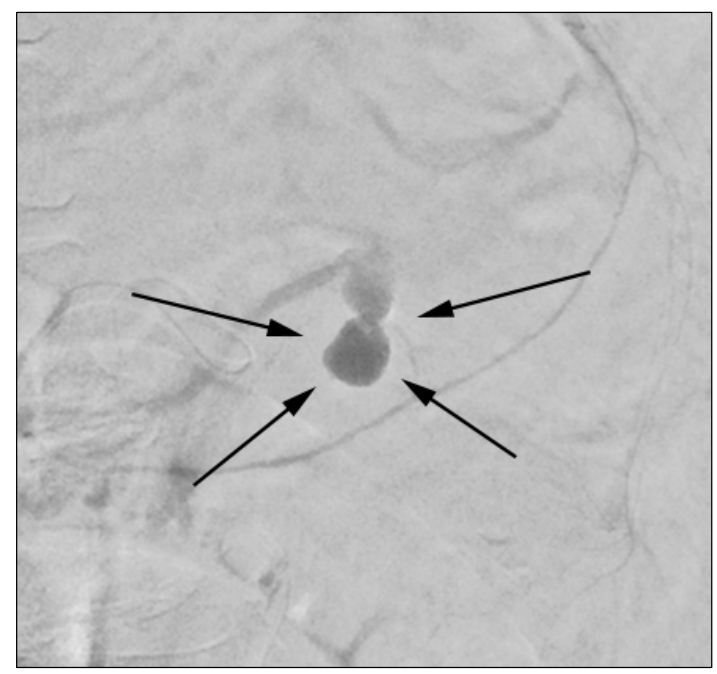

Fig. 3. Celiac angiography, arrows showing focal extravasation in the right gastroepiploic artery, without other anatomical defects, such as aneurysms.

to the emergency room. At that time, her blood pressure was 64/42 mmHg and her heart rate was 101 beats/min. Her initial hemoglobin count of $9.8 \mathrm{~g} / \mathrm{dL}$ had dropped to $8.6 \mathrm{~g} / \mathrm{dL}$. Contrast-enhanced abdominal CT showed extraluminal active bleeding with a hematoma around the gastric antrum without free air (Fig. 2). Since she had recently undergone endoscopic biopsy, we performed an emergency gastroscopy suspecting biopsy site bleeding; however, no intragastric bleeding was observed. Aortography was performed through the femoral artery at the celiac axis level until the gastroduodenal artery. Celiac angiography showed focal extravasation of the right gastroepiploic artery (Fig. 3). Transcatheter arterial embolization (TAE) was performed using an n-butyl cyanoacrylate mixture and microcoil. The patient was prescribed clopidogrel 72 hours after the bleeding because the hematoma had decreased on the follow-up CT. She was discharged on day 7 of hospitalization due of absence of further bleeding.

\section{DISCUSSION}

ISIH, first reported by Barber in 1909, ${ }^{1}$ was later referred to as abdominal apoplexy by Green and Power. ${ }^{2}$ This condition occurs because of a tear in an intra-abdominal visceral vessel, spontaneously and without any definitive causes. In the study by Stanley and Zelenock, ${ }^{3}$ $60 \%$ of splenic aneurysms were reported in the splenic artery, 20\% in the hepatic artery, 5.5\% in the superior middle artery, $4 \%$ in the celiac artery, and 3\% in the gastroepiploic artery. The incidence of a gastroepiploic artery rupture is low, and spontaneous, non-aneurysmal gastroepiploic artery rupture is extremely rare.

Intra-abdominal hemorrhage may be secondary to blunt trauma, aneurysmal rupture, solid organ malignancy (hepatic or renal), or inflammatory erosive processes (pancreatitis or pseudocyst). Bleeding can be intraperitoneal or retroperitoneal and is often found in association with hypertension (33 50\%) and atherosclerosis (80 87\%). ${ }^{4}$ Atherosclerosis can degenerate the tunica media, causing aneurysms and making the visceral arteries susceptible to rupture. Other risk factors include rheumatoid arthritis, systemic lupus erythematosus, and polyarteritis nodosa-which are associated with arterial involvement. The clinical presentation of ISIH varies, although the universal symptoms include abrupt abdominal pain and shock.

Most published case reports on ISIH involve a gastroepiploic artery aneurysm rupture. According to the seven cases reported since 2003, aneurysms were observed in all cases with the exception of one case in which the cause was uncertain (Table 1). However, we report a case of spontaneous gastroepiploic artery rupture without a definitive aneurysm that occurred after endoscopy. An aneurysm was not clearly observed on a CT scan taken 2 
Table 1. Reported Cases of Ruptured RGEA

\begin{tabular}{|c|c|c|c|c|c|c|c|c|}
\hline No & Study & Country & Age & Sex & Symptoms/underlying disease & Aneurysm/rupture or not & Treatment & Outcome \\
\hline 1 & $\begin{array}{l}\text { Yamabuki et al. }^{8} \\
(2003)\end{array}$ & Japan & 75 & $\mathrm{~F}$ & None & $(+) /$ not & OS & Alive \\
\hline 2 & $\begin{array}{l}\text { Hassani et al. }^{4} \\
\text { (2009) }\end{array}$ & Morocco & 64 & $\mathrm{~F}$ & $\begin{array}{l}\text { Abdominal pain, shock } \\
\text { Recurrent abdominal discomfort } \\
\text { HTN }\end{array}$ & Uncertain & Os & Alive \\
\hline 3 & Kim et al..$^{9}(2010)$ & Korea & 65 & M & $\begin{array}{l}\text { Abdominal pain, poor oral intake } \\
\text { COPD, asthma }\end{array}$ & $(+) /$ not & OS & Alive \\
\hline 4 & $\begin{array}{l}\text { Yamada et al. } \\
(2016)\end{array}$ & Japan & 20 & $\mathrm{~F}$ & $\begin{array}{l}\text { Abdominal pain, shock } \\
\text { Fibromuscular dysplasia }\end{array}$ & $(+) /$ yes & TAE & Alive \\
\hline 5 & $\begin{array}{l}\text { Sarigoz et al. } \\
\text { (2018) }\end{array}$ & Turkey & 57 & $\mathrm{~F}$ & $\begin{array}{l}\text { Abdominal pain, syncope } \\
\text { HTN, atherosclerotic heart } \\
\text { disease }\end{array}$ & $(+) /$ yes & OS & Alive \\
\hline 6 & $\begin{array}{l}\text { Takemoto et al. }{ }^{12} \\
(2017)\end{array}$ & Japan & 65 & $\mathrm{~F}$ & Abdominal \& back pain & $(+) /$ yes & OS & Alive \\
\hline 7 & $\begin{array}{l}\text { Ishimine et al. }{ }^{13} \\
(2018)\end{array}$ & Japan & 80 & $\mathrm{~F}$ & $\begin{array}{l}\text { Abdominal pain } \\
\text { Bronchiectasis }\end{array}$ & $(+) /$ yes & TAE & Alive \\
\hline
\end{tabular}

RGEA, right gastroepiploic artery; F, female; OS, open surgery; HTN, hypertension; M, male; COPD, chronic obstructive pulmonary disease; TAE, transarterial embolization.

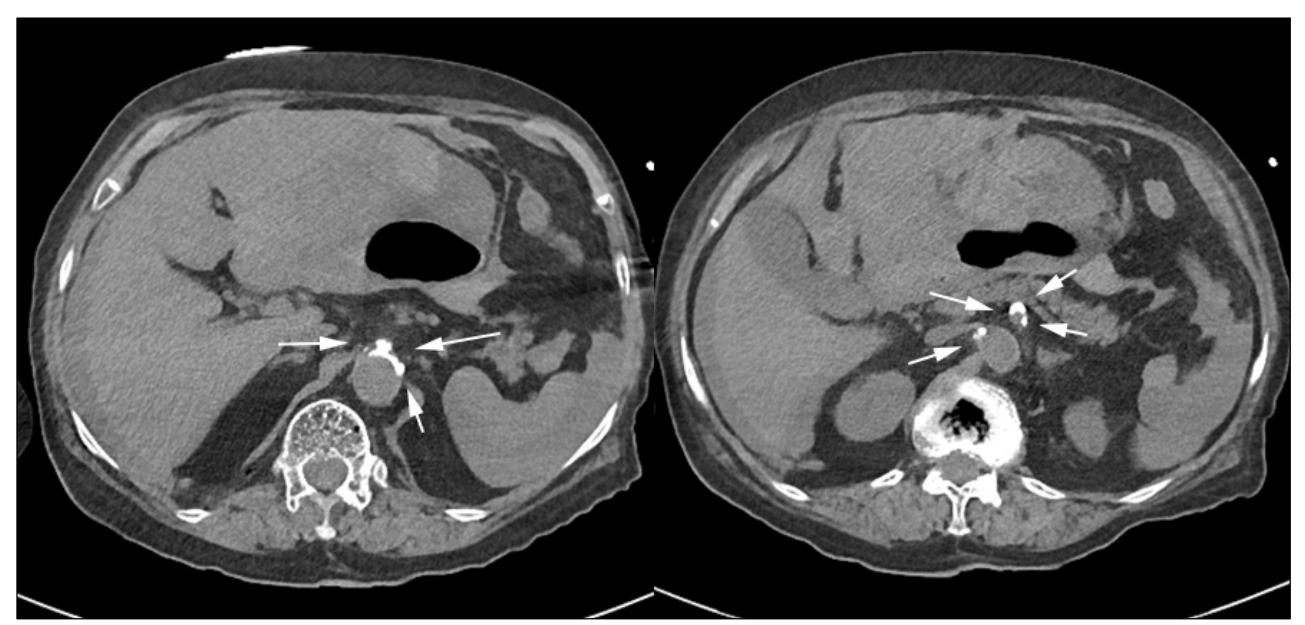

Fig. 4. Abdominal CT (axial view), arrows showing calcification in the celiac trunk.

months before gastroscopy (Fig. 4). In our case, the patient had atherosclerosis and hypertension for which she had undergone percutaneous intervention 2 months prior. Although enhanced chest CT did not reveal an aneurysm in the gastroepiploic artery, calcification was observed at the celiac trunk and at the branches of the common hepatic and splenic arteries (Fig. 4). As a result of these changes, an aneurysm may have occurred rapidly; as the blood flow velocity increased in the narrowed vascular system, the pressure in the gastroepiploic artery may have increased, resulting in rupture. In such a scenario, it is important to check for the symptoms of abdominal pain and hypovolemic shock and to make a quick diagnosis. CT is the most important imaging modality in emergency settings. With CT scans, intravenous contrast is highly recommended because its effectiveness in locating active bleeding has been proven.

Gastrointestinal bleeding is a potentially life-threatening abdominal emergency, with reported mortality rates of up to $10 \% .^{5}$ In patients with an unclear bleeding source or a 
high-risk status for surgical intervention, TAE should be advocated to identify bleeding sources and to provide bleeding control by embolization of the specific bleeding artery. ${ }^{6}$ TAE has been performed extensively and has been shown to be effective in controlling hemorrhage and decreasing mortality.

In summary, in this case, a patient who was receiving dual antiplatelet therapy developed spontaneous gastroepiploic artery rupture after diagnostic gastroscopy. She was treated with embolization without laparotomy, with no complications. There could have been unidentified aneurysmal ruptures, although no aneurysms were observed in the previous CT images. We need to consider spontaneous rupture of the visceral arteries in elderly individuals with hypertension or atherosclerosis when abrupt abdominal pain or shock occurs. This is the first case report of idiopathic spontaneous rupture of the right gastroepiploic artery successfully managed by TAE in South Korea.

\section{CONFLICT OF INTEREST}

No potential conflict of interest relevant to this article was reported.

\section{ORCID}

$\begin{array}{ll}\text { Do Young Jung } & \text { (D https://orcid.org/0000-0002-8060-452X } \\ \text { Hye-kyung Jung } & \text { (D https://orcid.org/0000-0002-6653-5214 } \\ \text { Yun Mi Ko } & \text { (D https://orcid.org/0000-0002-0211-4605 } \\ \text { Ayoung Lee } & \text { (D https://orcid.org/0000-0002-0692-8200 } \\ \text { Ji Taek Hong } & \text { (D https://orcid.org/0000-0002-6310-2958 } \\ \text { Chang Mo Moon } & \text { (D https://orcid.org/0000-0003-2550-913X } \\ \text { Seong Eun Kim } & \text { (D https://orcid.org/0000-0002-6310-5366 } \\ \text { Chung Hyun Tae } & \text { (D https://orcid.org/0000-0002-0764-7793 } \\ \text { Ki Nam Shim } & \text { (D https://orcid.org/0000-0003-4004-6292 } \\ \text { Sung Ae Jung } & \text { (D) https://orcid.org/0000-0001-7224-2867 } \\ \text { Ran Kim } & \text { (D) https://orcid.org/0000-0002-0241-2071 }\end{array}$

Sun Young Choi (D) https://orcid.org/0000-0003-2488-1183

\section{REFERENCES}

1. Barber MC. Intra-abdominal haemorrhage associated with labour. Br Med J 1909;2:203-204.

2. Green WT, Powers JH. Intra-abdominal apoplexy. Ann Surg 1931;93:1070-1074.

3. Stanley JC, Zelenock GB. Splanchnic artery aneurysms. In: Rutherford RB, ed. Vascular surgery. 4th ed. Philadelphia: WB Saunders, 1995:1124-1139.

4. Hassani KI, Bounekar A, Gruss JM. Spontaneous rupture of the right gastroepiploic artery: unusual cause of acute abdomen and shock. World J Emerg Surg 2009;4:24.

5. Balaban DV, Strâmbu V, Florea BG, Cazan AR, Brătucu M, Jinga M. Predictors for in-hospital mortality and need for clinical intervention in upper GI bleeding: a 5-year observational study. Chirurgia (Bucur) 2014;109:48-54.

6. Kim PH, Tsauo J, Shin JH, Yun SC. Transcatheter arterial embolization of gastrointestinal bleeding with N-butyl cyanoacrylate: a systematic review and meta-analysis of safety and efficacy. $\mathrm{J}$ Vasc Interv Radiol 2017;28:522-531.e5.

7. Loffroy R, Favelier S, Pottecher P, et al. Transcatheter arterial embolization for acute nonvariceal upper gastrointestinal bleeding: indications, techniques and outcomes. Diagn Interv Imaging 2015;96:731-744.

8. Yamabuki T, Kojima T, Shimizu T, et al. Successful laparoscopic right gastroepiploic aneurysmectomy: report of a case. Surg Today 2003;33:932-936.

9. Kim H, Cho YP, Moon KM, Park SJ, Kwon TW. A right gastroepiploic artery aneurysm treated by surgical excision. J Korean Surg Soc 2010;78:423-425

10. Yamada M, Nakada TA, Idoguchi K, Matsuoka T. Fibromuscular dysplasia presenting as hemorrhagic shock due to spontaneous rupture of a right gastroepiploic artery aneurysm. Am J Emerg Med 2016;34:677.e3-e5.

11. Sarigoz T, Carkit S, Topuz O, Ertan T, Koc A. Spontaneous rupture of right gastroepiploic artery aneurysm: a rare cause of hemorrhagic shock. Case report. Sao Paulo Med J 2018;136: 488-491.

12. Takemoto YK, Fujikuni N, Tanabe K, Amano H, Noriyuki T, Nakahara M. A rare case of spontaneous rupture of an aneurysm of the right gastric artery. Int J Surg Case Rep 2017;40:27-31.

13. Ishimine T, Tengan T, Nakasu A, Takara H. Successful transcatheter arterial embolization of a ruptured right gastroepiploic artery aneurysm: a case report. Int J Surg Case Rep 2018;51: 158-160. 